\title{
Use of pelvic ultrasound to monitor ovarian and uterine maturity in childhood onset anorexia
}

\section{nervosa}

\author{
Kelly Y C Lai, Rose de Bruyn, Bryan Lask, Rachel Bryant-Waugh, Matthew Hankins
}

\begin{abstract}
This study reports the use of pelvic ultrasound scanning in childhood onset anorexia nervosa. The aim was to determine the weight and weight for height ratio (wt/ht) that would correspond with ovarian and uterine maturity and therefore offer the optimal opportunity for the start or resumption of menstruation.

On initial assessment, all children had mean weight, wt/ht, ovarian and uterine volumes significantly below expected. At follow up, half the children had started or resumed menstruation. When compared with those who had persisting amenorrhoea, the recovered children had a significantly higher mean weight $(48.4 \mathrm{~kg}$ $v 43.8 \mathrm{~kg})$, mean wt/ht $(96.5 \%$ v $87.5 \%)$, mean ovarian volume $(6.2 \mathrm{ml} v 4.9 \mathrm{ml})$, and mean uterine volume $(14.6 \mathrm{ml} v 10.8 \mathrm{ml})$.

The study indicates that conventional target weight and wt/ht in anorexia nervosa may be too low to ensure ovarian and uterine maturity, and that pelvic ultrasound, which is well tolerated by this group of children, is a useful addition to their management.
\end{abstract}

(Arch Dis Child 1994; 71: 228-231)

One of the physical effects of anorexia nervosa is disturbance of the hypothalamic-gonadal axis, manifesting as amenorrhoea. It is thought to be related to the severe diet restriction and marked weight loss. Weight gain generally leads to a return of menses, but as many as $50 \%$ of adult patients continue to be amenorrhoeic or have irregular cycles years later, some despite maintaining a 'normal' weight. ${ }^{12}$

In children with anorexia nervosa, especially those whose illness predates the completion of

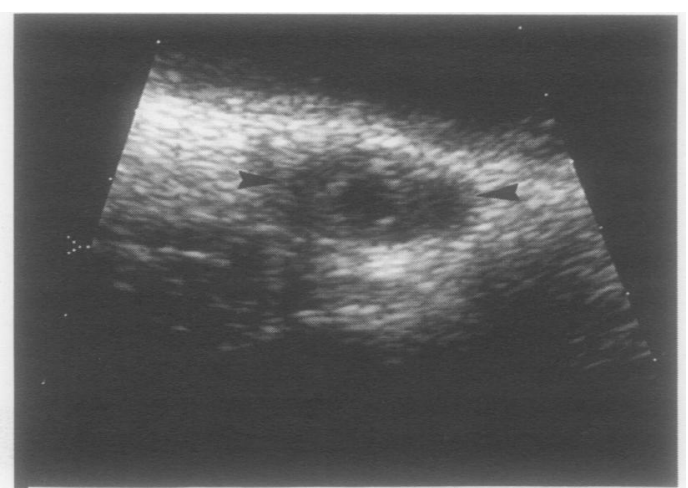

Figure 1 Normal prepubertal ovary lying behind the bladder with only small microfollicles present. The ovarian outline is indicated by two arrows. puberty, there is a real risk that pubertal development may be seriously impaired, leading to arrested physical growth and delayed menarche. ${ }^{3}$ Various medium term follow up studies have found outcomes similar to those of adult patients: normalisation of weight occurred in about two thirds of patients, but return or start of menses occurred in only $50-60 \% .^{4-7}$ It is evident that while 'normal weight' serves as an indicator of nutritional outcome, it does not necessarily denote other aspects of physical recovery, such as menstrual function.

An important advance in monitoring the physical effects of eating disorders is the use of high resolution ultrasound scanners for assessing the size and morphology of the uterus and ovaries. In the course of normal development, the ovaries are initially heterogeneous with small 1-2 mm microfollicles visible on scanning (fig 1). As puberty progresses, there is a gradual increase in size and number of ovarian follicles, that is the ovaries become 'multifollicular' (more than six follicles in each ovary measuring more than $4 \mathrm{~mm}$ ) (fig 2). A single follicle then becomes dominant, and develops into an ovulatory follicle when it exceeds $2 \mathrm{~cm}$ in diameter (fig 3). The ovarian volumes measure up to $3 \mathrm{ml}$, calculated according to the simplified formula for a prolate ellipsoid during childhood. ${ }^{3}$ The normal range in pubertal girls is $3.95 \pm 1.7 \mathrm{~cm},{ }^{38}$ and in young adults can be as high as $14 \mathrm{ml} .{ }^{9}$

The prepubertal uterus has a tear drop shape, with the cervix larger than the corpus (fig 4). After 6 years of age the uterus gradually elongates and the fundus develops and grows, so that the uterus is pear shaped by the time puberty is complete (fig 5). The normal pubertal uterine volume is $14.8 \pm 7.6 \mathrm{~cm} .{ }^{38}$ Treasure et al have used pelvic ultrasound scanning in adults to monitor the relationship between weight and ovarian and uterine size and morphology. ${ }^{10}$ They demonstrated that weight loss results in regression of the uterus and ovaries to prepubertal size and appearance. Pelvic ultrasound can therefore be used in determining 'target' body weights in adults with eating disorders.

This study is the first to report the use of serial pelvic ultrasound scanning in monitoring the regression and recovery of the ovaries and uterus in children with anorexia nervosa. Its aim was to determine the weight and weight for height ratio (wt/ht) that would correspond with ovarian and uterine maturity, and therefore ensure the start or resumption of menstruation. 


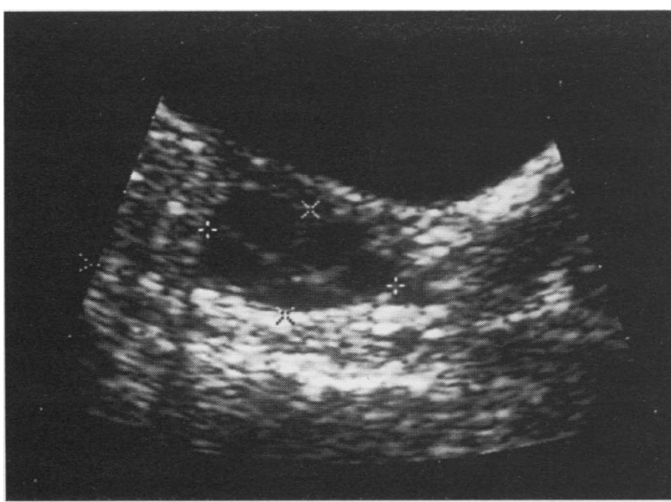

Figure 2 Multifollicular ovary demonstrating more than six follicles measuring more than $4 \mathrm{~mm}$ in diameter. This is a normal stage of development. The ovary is defined by calliper markers.

\section{Patients and methods}

The subjects consisted of a consecutive series of 26 girls diagnosed at the Hospital for Sick Children, Great Ormond Street, as having anorexia nervosa. Diagnosis was based on a checklist described by Fosson et al - that is, determined food refusal, weight loss, and any two or more of preoccupation with body weight, preoccupation with energy intake, distorted body image, fear of fatness, self induced vomiting, extensive exercising, or purging. ${ }^{11}$ (The more traditional diagnostic criteria of ICD-9 12 and DSM-III-R ${ }^{13}$ are not applicable to children. ${ }^{14}$ ) Serial pelvic ultrasound scanning was performed at the time of their initial assessment and at approximately three monthly intervals until menstruation started or returned.

Ultrasound examination was performed using a high resolution real time Acuson 128 scanner. Warmed gel was applied to the lower abdomen as a coupling agent. A full bladder was a prerequisite for the examination as it is used as an acoustic window to visualise the uterus and ovaries lying behind the bladder. The examinations were performed by an experienced paediatric radiologist (RdeB) familiar with the normal appearance and development of prepubertal and pubertal uterus and ovaries. Student $t$ tests were used for statistical comparisons.

The average age of the whole sample at referral was 13.5 years, with a range of 10.4-15.7 years. The average duration of

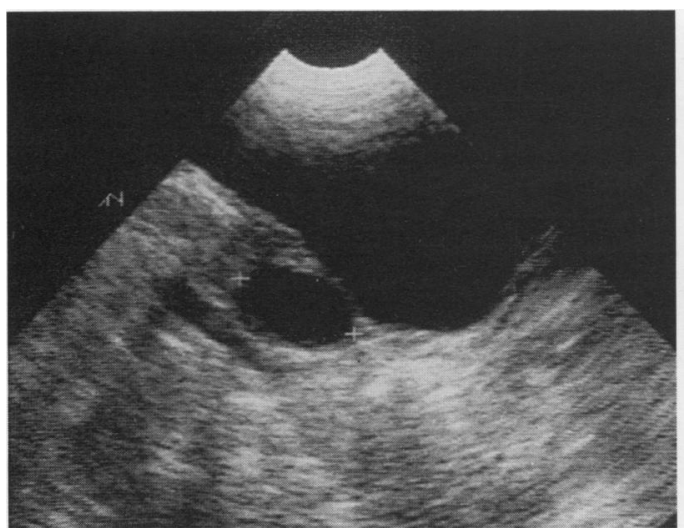

Figure 3 Ovary containing a dominant ovulatory follicle, as demonstrated by calliper markers.

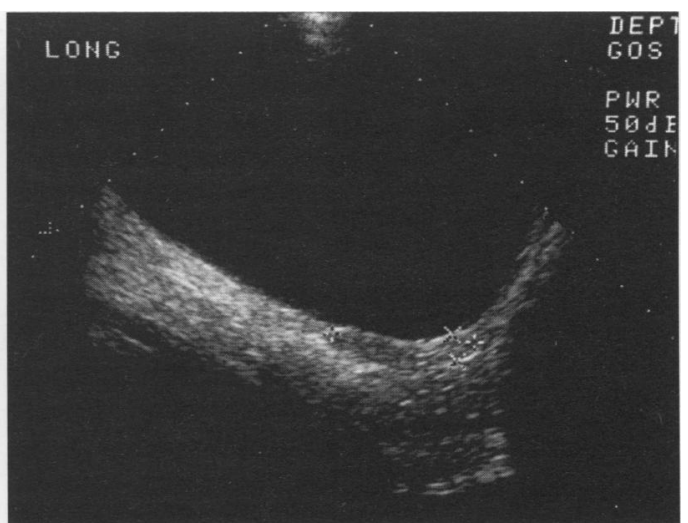

Figure 4 Longitudinal ultrasound scan through a normal prepubertal uterus. The uterus is tubular in shape with the cervix ( $x$ calliper) more prominent than the fundus.

symptoms before assessment was 11 months (range 3-37 months). Their mean weight was $37 \cdot 4 \mathrm{~kg}$ (range $28 \cdot 0-50.9 \mathrm{~kg}$, SD $6 \cdot 6$ ), and mean wt/ht according to the TannerWhitehouse standards ${ }^{15} 16$ was $81 \%$. (A wt/ht of less than $80 \%$ indicates a weight below the third centile and significant wasting.) A number of children had been nasogastrically fed before referral, thus raising the mean wt/ht for the sample. All 26 children were actively anorectic at the time of initial assessment.

Twelve $(46 \%)$ of the children had never menstruated (the primary amenorrhoea group), and the other 14 (54\%) had menstruated at least once (the secondary amenorrhoea group). These two groups were similar in age at presentation to the hospital and duration of symptoms. The primary amenorrhoea group was significantly lighter than the secondary amenorrhoea group in both actual body weight (mean $32.4 \mathrm{~kg}$, range $28.0-40.9 \mathrm{~kg}$, SD $4.6, v 41.7 \mathrm{~kg}$, range $34.0-50.9 \mathrm{~kg}$, SD $4.8, \mathrm{p}<0.001$ ), and $\mathrm{wt} / \mathrm{ht}$ $(76.3 \%$, range $60-85 \%$, SD $7 \cdot 6, v 85 \cdot 1 \%$, range $69-97 \%$, SD $8.5, \mathrm{p}<0.01$; see table 1 ).

All the children were treated using a comprehensive approach, either as inpatients or outpatients. ${ }^{17}$

\section{Results}

INITIAL OVARIAN AND UTERINE VOLUMES

The mean ovarian and uterine volumes at the time of the first scan are shown in table 1. The

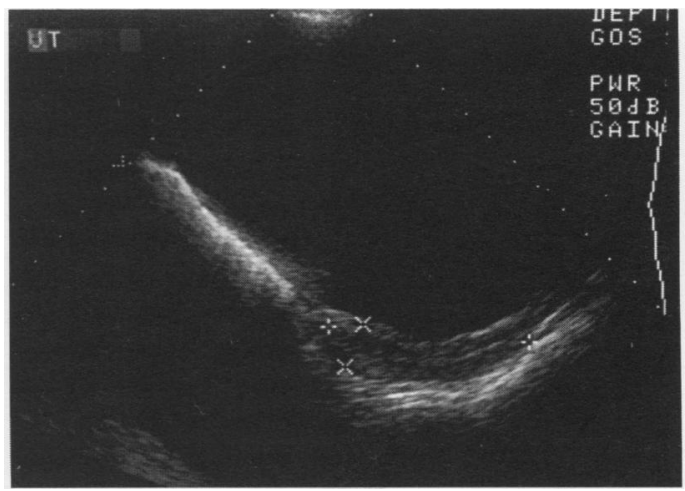

Figure 5 Longitudinal section of the normal adult uterus. The fundus has grown and is now prominent compared with the cervix. The endometrium appears as an echogenic midline echo. 
Table 1 Characteristics of primary and secondary amenorrhoea groups at referral; values are mean (SD)

\begin{tabular}{|c|c|c|c|}
\hline & $\underset{(n=12)}{\text { Primary }}$ & $\begin{array}{l}\text { Secondary } \\
(n=14)\end{array}$ & t Test \\
\hline $\begin{array}{l}\text { Age (years) } \\
\text { Weight (kg) } \\
\text { Wt/ht }(\%) \\
\text { Ovarian volume }(\mathrm{ml})^{\star} \\
\text { Uterine volume }(\mathrm{ml}) \dagger\end{array}$ & $\begin{array}{c}13 \cdot 0(1 \cdot 3) \\
32 \cdot 4(4 \cdot 6) \\
76 \cdot 3(7 \cdot 6) \\
2 \cdot 7(0 \cdot 8) \ddagger \\
3 \cdot 4(2 \cdot 2)\end{array}$ & $\begin{array}{r}14 \cdot 0(1 \cdot 2) \\
41 \cdot 7(4 \cdot 8) \\
85 \cdot 1(8 \cdot 5) \\
3.6(1 \cdot 6) \\
7 \cdot 4(3 \cdot 1)\end{array}$ & $\begin{array}{l}\text { NS } \\
p<0.001 \\
p<0.01 \\
p<0.05 \\
p<0.001\end{array}$ \\
\hline
\end{tabular}

^Expected ovarian volume $=3.95(1.7) \mathrm{ml}$

†Expected uterine volume $=14 \cdot 8(7 \cdot 6) \mathrm{ml}$

$\neq \mathrm{p}<0.001$ compared with expected norms.

mean uterine volume was significantly smaller than expected norms $(p<0.001)$ in both amenorrhoea groups, and more markedly so in the primary group.

The mean ovarian volume was also reduced: the reduction in the mean for the primary amenorrhoea group was more marked $(p<0.001)$ while the mean for the secondary amenorrhoea group was within the lower part of the normal range.

FOLLOW UP (TABLE 2)

Altogether 13 children $(50 \%)$ started or recommenced menstruation within 12 months of treatment: six from the primary amenorrhoea group $(50 \%)$ and seven from the secondary amenorrhoea group (50\%). Those who remained amenorrhoeic were followed up. The results below refer either to the time at which menstruation started or returned, or for the amenorrhoea group, to follow up at a mean of 18 months after the first scan.

The menstruating group had reached significantly higher weights (mean $48.4 \mathrm{~kg}$, range 45.4-53.5 kg, SD 2.0) and greater wt/ht (96.5\%, range $90-108 \%$, SD 4.4 ) than those who remained amenorrhoeic $(43.8 \mathrm{~kg}$, range $35.0-51.5 \mathrm{~kg}$, SD 4.3 and $87.5 \%$, range $76-96 \%$, SD 5.9). Similarly the menstruating group had reached significantly higher ovarian volumes $(6.2 \mathrm{ml}$, range $4.7-8.3 \mathrm{ml}, \mathrm{SD} 1.4)$ and uterine volumes $(14.6 \mathrm{ml}$, range $11.6-19.4 \mathrm{ml}$, SD 2.7) than those who remained amenorrhoeic $(4.9 \mathrm{ml}$, range $2.0-6.5 \mathrm{ml}$, SD 1.6 and $10.8 \mathrm{ml}$, range $6 \cdot 1-16 \cdot 0 \mathrm{ml}, \mathrm{SD} 5 \cdot 2$; table 2 ).

Increases in uterine and ovarian volume were observed with weight gain. The mean ovarian volume of those who were menstruating was similar to that expected for age and significantly greater than that of the nonmenstruating girls. Similarly the mean uterine volume of those who were menstruating was within the upper part of the normal range, and significantly greater than that of the nonmenstruating girls.

Table 2 Characteristics of menstruating and nonmenstruating groups at follow up; values are mean (SD)

\begin{tabular}{|c|c|c|c|}
\hline & $\begin{array}{l}\text { Menstruating } \\
(n=13)\end{array}$ & $\begin{array}{l}\text { Non- } \\
\text { menstruating } \\
(n=13)\end{array}$ & t Test \\
\hline $\begin{array}{l}\text { Age (years) } \\
\text { Weight }(\mathrm{kg}) \\
\text { Wt/ht }(\%) \\
\text { Ovarian volume (ml) } \\
\text { Uterine volume (ml) }\end{array}$ & $\begin{array}{r}14.5(1 \cdot 4) \\
48 \cdot 4(2 \cdot 0) \\
96 \cdot 5(4 \cdot 4) \\
6 \cdot 2(1 \cdot 4) \\
14 \cdot 6(2 \cdot 7)\end{array}$ & $\begin{array}{c}15 \cdot 2(1 \cdot 7) \\
43 \cdot 8(4 \cdot 3) \\
87 \cdot 5(5 \cdot 9) \\
4 \cdot 9(1 \cdot 6) \\
10 \cdot 8(5 \cdot 2)^{\star}\end{array}$ & $\begin{array}{l}\text { NS } \\
p<0.005 \\
p<0.001 \\
p<0.05 \\
p<0.005\end{array}$ \\
\hline
\end{tabular}

${ }^{\star} \mathrm{p}<0.05$ compared with expected norms.

\section{Discussion}

The findings of our study confirm that, as in the case of adults, the ovaries and uterus of children presenting with anorexia nervosa are smaller than expected for their age. (Although their morphologies have not been presented here, our results concur with findings in adults with anorexia nervosa that at initial assessment, the ovaries and uterus are immature in appearance and content. ${ }^{10}$ ) This reduction in size is present in both the primary and secondary amenorrhoea groups, and is more striking in the former. Among the children with secondary amenorrhoea, it is indicative of regression of the pelvic organs as a result of weight loss. In those who are premenarcheal, it is possible that their persistently low weight, or failure to gain weight, has interrupted normal pubertal development so that the ovaries and uterus fail to reach sufficient maturity for menstruation to start.

During weight gain, both the ovaries and uterus gradually increase in size. A return, or start, of menstruation occurs when both the ovaries and uterus have reached maturity after sustained weight gain.

It is clear from our findings, that the target commonly set in anorexia nervosa for weight (44-45 kg) and wt/ht (93-95\%) are far too low, in that pelvic ultrasound shows that ovarian and uterine maturity occurs at a mean weight of $48 \mathrm{~kg}$ and mean wt/ht of $96.5 \%$. This probably explains why such a large proportion of young people with anorexia nervosa have persisting amenorrhoea. Target weight and wt/ht need to be set higher than previously suggested. Pelvic ultrasound scanning enables the monitoring of ovarian and uterine maturation and the setting of correct target weight and wt/ht. This has considerable clinical significance, not only for the setting of correct targets, but also because children with anorexia nervosa tend to accept as gospel the target weight initially given. They then find it very difficult to accept the setting of a higher target, should the initial one prove too low. Finally, we noted with interest that pelvic ultrasound scanning appeared to motivate the children in a way that weight and wt/ht targets do not.

\section{Conclusion}

Pelvic ultrasound is an inexpensive, rapid, non-invasive, and easy to perform investigation that is well tolerated by children with anorexia nervosa. Our results indicate that previous target weight and wt/ht have been set too low. A healthy target weight is $48 \mathrm{~kg}$, weight for height ratio $96.5 \%$, ovarian volume $6 \mathrm{ml}$, and uterine volume $15 \mathrm{ml}$. Pelvic ultrasound scanning enables us to determine weight and wt/ht that correspond with the start or return of menstruation.

This study was supported by the Gordon Carlton Memorial Fund.

We wish to thank Professor A Fosson, department of pediatrics, University of Kentucky, for his helpful comments; Dr L Kroll, now senior registrar in child psychiatry, Tavistock Clinic, for her assistance in the preparation of the study; and staff of the Mildred Creak Unit for their help in the ultrasound investigations. 
1 Hsu LKG. The outcome of anorexia nervosa: a reappraisal Psychol Med 1988; 18: 807-12.

2 Steinhausen H-CH, Rauss-Mason C, Seidel R. Follow up studies of anorexia nervosa; a review of four decades of outcome research. Psychol Med 1991; 21: 447-54.

3 Russell GFM. Premenarchal anorexia nervosa and its sequelae. F Psychiatr Res 1985; 19: 363-9.

4 Hawley RM. The outcome of anorexia nervosa in younger subjects. Br f Psychiatry 1985; 146: 657-60.

5 Bryant-Waugh R, Knibbs J, Fosson A, Kaminski Z, Lask B. Long term follow up of patients with early onset anorexia Long term follow up of patients with ear

6 Walford G, McCune N. Long-term outcome in early onset anorexia nervosa. Br f Psychiatry 1991; 159: 383-9.

7 Jarman FC, Rickards WS, Hudson II. Late adolescent outcome of early onset anorexia nervosa. $\mathcal{f}$ Paediatr Child Health 1991; 27: 221-7.

8 Salardi S, Orsini LF, Cacciari E, Bovicelli L, Tassoni P, Reggiani A. Pelvic ultrasonography in premenarchal girls: relation to puberty and sex hormone concentrations. Arch Dis Child 1985; 60: 120-5.

9 Munn CS, Kiser LC, Wetnzer SM, Baer JE. Ovary volume in young and premenopausal adults: US determination. in young and premenopausal

10 Treasure JL, Wheeler M, King EA, Gordon PAL, Russell
GFM. Weight gain and reproductive function: ultrasonographic and endocrine features in anorexia nervosa. Clin Endocrinol (Oxf) 1988; 29: 607-16.

11 Fosson A, Knibbs J, Bryant-Waugh R, Lask B. Early onse anorexia nervos. Arch Dis Child 1987; 62: 114-8.

12 World Health Organisation. The 9th revision of the international classification of diseases. Geneva: WHO, 1978.

13 American Psychiatric Association. Diagnostic and Statistical Manual of Mental Disorders (third edition revised). Washington: American Psychiatric Association, 1987.

14 Lask B, Bryant-Waugh R, eds. Childhood onset of anorexia nervosa and related eating disorders. Hove, Sussex: nervosa and related eating disorders.

15 Tanner JM, Whitehouse RH, Takaishi M. Standards from birth to maturity for height, weight, height velocity and weight velocity: British children 1965. Part 1. Arch Dis Child 1966; 41: 454-71.

16 Tanner JM, Whitehouse RH, Takaishi M. Standards from birth to maturity for height, weight, height velocity and weight velocity: British children 1965. Part 2. Arch Dis Child 1966; 41: 613-35.

17 Lask B, Bryant-Waugh R, eds. Management overview. Childhood onset of anorexia nervosa and related eating disorders. Hove, Sussex: Laurence Erlbaum Associates, 1993. orders. H. 